\title{
Study and Dimensioning of the Tanks Dedicated to a Compressed Air Energy Storage system (CAES)
}

\author{
I. Rais ${ }^{1}$ and H. Mahmoudi ${ }^{2}$ \\ ${ }^{1}$ Mohamadia Engineering School, Mohammed V university, Morocco \\ ${ }^{2}$ Power Electronic and Control Team (EPCT), Department of Electrical Engineering, Morocco
}

\begin{abstract}
Article Info
Article history:

Received: October 2, 2017

Revised: April 14, 2018

Accepted: May 3, 2018

Keyword:

CAES

CAM

Compressor

ABSTRACT

The fundamental idea of storage is to transfer available energy During periods of low demand, using only a fraction of the fuel that would be consumed by the standard production machine (gas turbine, thermal engine, etc.). The main role of energy storage is therefore to introduce an energy degree of freedom to decouple Consumers and the producer by supplying or Delivering the difference between these two powers. In this paper is this paper presents a brief study and dimensioning of compressed air storage tanks to a hybrid system wind-PV. adopts the CAES system as a storage agent. starting with the technical criteria on which the choice of reservoirs is based and the mechanical constraints that must be taken into consideration for dimensioning of the reservoirs
\end{abstract}

Reservoir

energy density

charging time

discharging time
Copyright (c) 2018 Institute of Advanced Engineering and Science. All rights reserved.

Corresponding Author:

Ilham Rais

Power Electronic and Control Team (EPCT)

Rabat, Morocco

Email: ilhamrais@research.emi.ac.ma

\section{INTRODUCTION}

In most isolated areas, the diesel generator is the main source of electrical power.that poses immense technical challenges And financial. This generation of electricity is relatively inefficient, very costly and responsible for the emission of large quantities of greenhouse gases (GHGs). The use of wind-solar (JES) twinning in these autonomous networks could Thus reducing operating deficits [5][7].

However, the profitability of the JES is achieved on the condition of obtaining a high penetration rate of wind and/or solar energy, which is possible only by using storage systems [8] the solution proposed which meets all the technical and financial requirements while ensuring a reliability of electricity supply to the isolated sites. It is the hybrid wind-photovoltaic system with storage of compressed air [1]. The use of compressed air as an energy storage agent is as well suited to wind and solar production as it is to diesels. The principal idea for the storage of electrical energy By wind turbine plant and Photovoltaic array as a source of energy coupled with two Pneumatic machines: The first is a compressor driven by an electric motor and the second is an compressed air motor which drives in turn an alternator [1].

During windy period the turbine directly supplies the isolated site on electricity and Surplus energy will be used by the electric motor to drive the compressor to recharge the compressed air in the trivial tanks. In the absence of wind turbine the photovoltaics energy will follow the same principle. In the absence of the two energy sources compressed, the air will be relaxed in the compressed air motor which will drive in turn the generator to supply electricity at the isolated site. This hybrid system would act in real time in order to maintain the balance between the power generated and consumed by achieving a remarkable reduction in fuel consumption whatever the level of the power demanded. the following paper will present a brief study of the selection criteria of the reservoirs and the dimensioning of this latters as the most interesting elements in the compression chain [1][12]. 


\section{TECHNICAL CHARACTERISTIC FOR THE CHOICE OF RESERVOIRS}

The choice of tanks suitable for the proposed compressed air storage system does not come at random but there are several technical criteria which characterize them we cite among them [4][2]:

energy density of storage

The flexibility of location and specific site requirements.

Storage capacity.

The self-discharge.

The yield of the storage system

\subsection{Energy density of storage}

An open gas cycle system allows complete polytropic expansion of air compressed from the maximum pressure to atmospheric pressure. this allows full exploitation of the energy stored as compressed air. For a $1 \mathrm{~m} 3$ unit of volume, the storage energy density can be expressed by the following equation [3]:

$$
W=K \frac{n N P_{r}}{n-1}\left(1-\left(\frac{P_{a}}{P_{r}}\right)^{\frac{n-1}{n N}}\right)
$$

with

$K=2.777810^{-6}$ is the energy conversion constant in $\mathrm{kWh}, \mathrm{N}$ is the number of expansion stages of the CAM, $P_{a}$ is the atmospheric pressure and $P_{r}$ is the storage pressure. The figure above gives an idea of the amount of

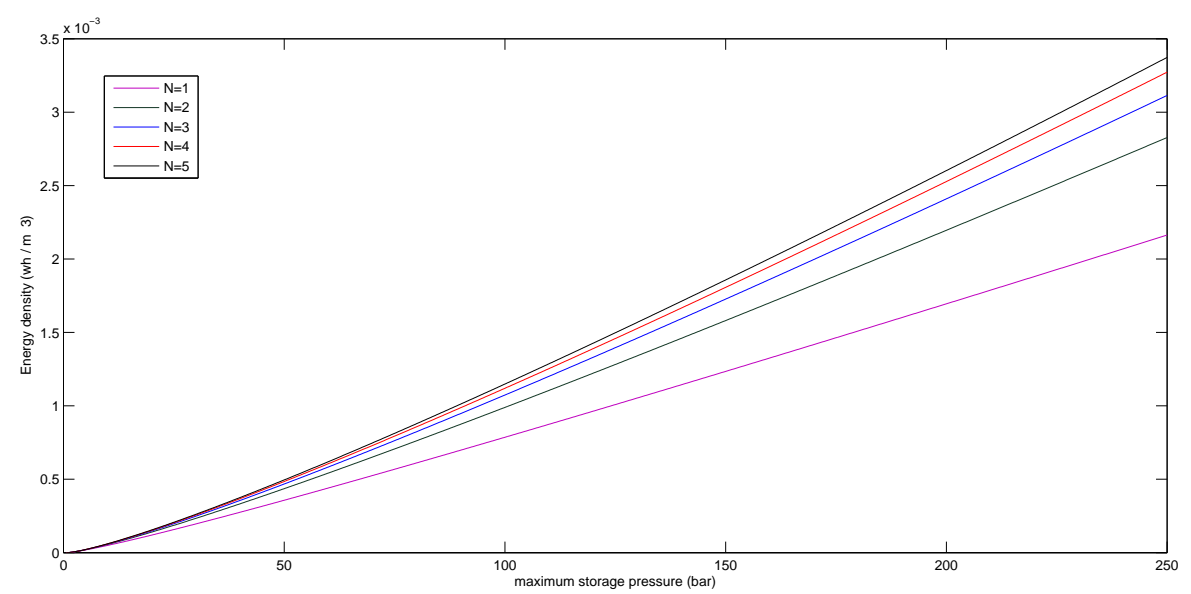

Figure 1. variation of the energy density as a function of the number of stage and the storage pressure

energy stored in a given volume of air. It can be noticed that by increasing the maximum allowable pressure in the tank this quantity can be increased.

Thus, the higher the number of stages of the air expansion in the CAM increases, the more energy density per $m^{3}$ increases and consequently the mechanical work (electrical idem) develops closer to its maximum value.

In practice, the compressed air expansion process must be stopped once the pressure in the tank drops below the minimum pressure, $P_{r m}$, required for the operation of the system. Indeed, below this pressure limit, the power delivered becomes so low that the operation of the system becomes ineffective. The value of $P_{r m}$ depends on the nature of the application. Therefore, in the case where $P_{r m}$ is greater than atmospheric pressure $P_{a}$, unexploited energy, $W_{\text {unex }}$, will remain in the air reservoir. this energy can be expressed as follows:

$$
W_{\text {unex }}=K \frac{n N P_{r m}}{n-1}\left(1-\left(\frac{P_{a}}{P_{r m}}\right)^{\frac{n-1}{n N}}\right)
$$

Consequently, the effective energy density $W_{\text {ef }}$ will be reduced and equal to the difference between the total available energy density $W$ and the unused energy density $W_{\text {unex }}$, hence:

$$
W_{e f}=W-W_{\text {unex }}
$$


The Figure 2 shows the effective energy density as a function of the pressure minimum of operation, $P_{r m}$, for different values of the maximum pressure $P_{r}$. It is that the lower the minimum pressure, the higher the effective energy density.

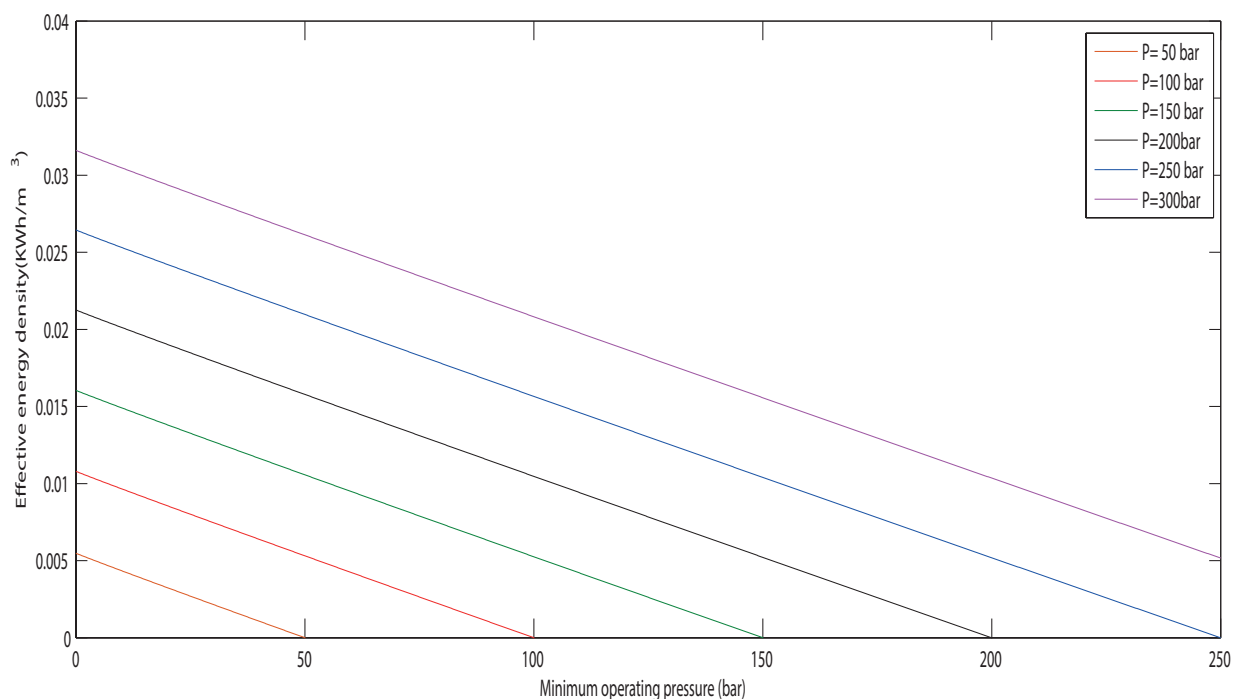

Figure 2. influence of minimum operating pressure on the density of energy

For a good evaluation of the unused energy, the pressure utilization factor (PUF) for an open gas cycle can be defined as:

$$
P U F=1-\frac{W_{\text {unex }}}{W}
$$

It is easy to deduce from this equation that PUF $=1$ if $P_{r m}=P_{a}$ and PUF $=0$ if $P_{r m}=\mathrm{P}$. The Figure 3 shows the variations of PUF as a function of the minimum storage pressure for a relaxation which is carried out in 5 step .

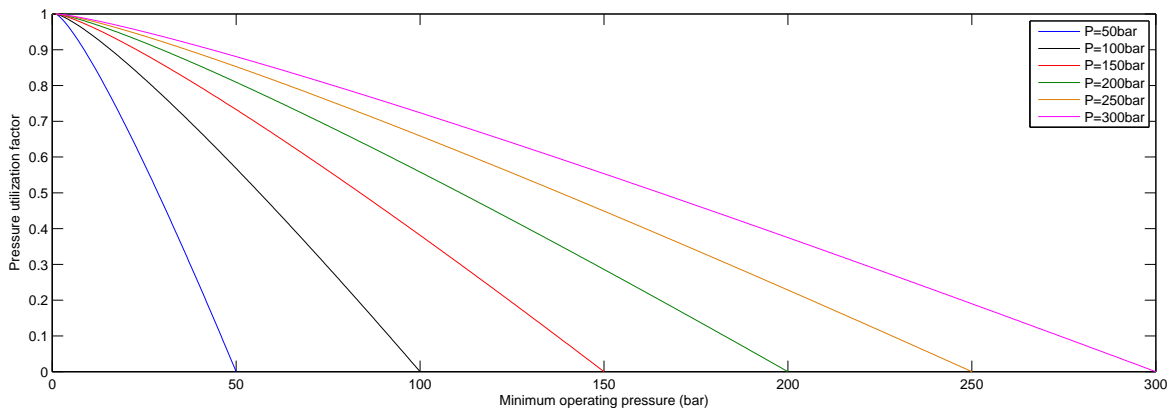

Figure 3. Variation of PUF as a function of the minimum operating pressure

\section{MECHANICAL CONSTRAINTS}

Currently available materials can store a high density up to pressures of the order of 500 bar; for the proposed study we will considered a spherical tanks, relatively slim whose pressure inside has a small thickness is supposed constant, because the storage pressure $P_{r}$ depends on the maximum breaking stress, $\sigma$, and of the dimensions of the reservoir, the expression that connects these parameters is the following [9][6]:

$$
\frac{e_{r}}{D_{r}}=\frac{P_{r}}{4 \sigma}
$$

With:

$e_{r}$ and $D_{r}$ are, respectively, the thickness and the diameter of the storage tank. knowing that $R_{\text {int }}=\frac{D_{r}}{2}$ is the 
internal radius of the reservoir, $R_{\text {ext }}$ is the outer radius of the reservoir of storage and $e_{r}=R_{\text {ext }}-R_{\text {int }}$, the volumes of stored air and the reservoir are respectively :

$$
\begin{aligned}
V & =\frac{4}{3} R_{i n t}^{3} \pi \\
V_{r} & =\frac{4}{3} R_{e x t}^{3} \pi
\end{aligned}
$$

The volume of the material used in the manufacture of the tank is then:

$$
V_{\text {matr }}=V-V_{r}=\frac{4}{3} \pi\left(R_{\text {ext }}-R_{\text {int }}\right)\left(R_{\text {ext }}^{2}+R_{\text {ext }} R_{\text {int }}+R_{\text {int }}^{2}\right)
$$

The hypothesis that the reservoir has a small thickness makes it possible to simplify the second term of the previous equation in $3 R_{\text {int }}^{2}$ and the expression of $V_{\text {matr }}$ becomes as follows:

$$
V_{\text {matr }}=\frac{4}{3} e_{r} \pi\left(3 R_{\text {int }}^{2}\right)
$$

From the above equations, a relation between the volume of air stored, V, as well as the volume of materials used in the manufacture of the tank, $V_{\text {matr }}$, can be deduced, hence:

$$
\frac{V_{\text {matr }}}{V}=\frac{\frac{4}{3} e_{r} \pi\left(3 R_{\text {int }}^{2}\right)}{\frac{4}{3}\left(R_{i n t}^{3}\right) \pi}=\frac{3 e_{r}}{R_{\text {int }}}=\frac{6 e_{r}}{D_{r}}=\frac{3 P_{r}}{2 \sigma}
$$

The relationship between the mass of the materials of a spherical reservoir, $M_{m a t r}$, and the energy stored, E, can then be expressed by the following relation

$$
\frac{M_{\text {matr }}}{E_{s t}}=\frac{\operatorname{Vmatr} \rho}{\frac{n}{(n-1) \eta} N\left(1-\left(\frac{P}{P_{a}}\right)^{\frac{1-n}{n N}}\right)}=\frac{3(n-1) \eta \rho}{2 N n N n\left(1-\left(\frac{P}{P_{a}}\right)^{\frac{1-n}{n N}}\right) \sigma}
$$

$\eta$ is the overall efficiency of the conversion chain between the PV-wind hybrid system and the storage tank and $E_{s t}$ is the stored energy which can be defined by:

$$
E_{s t}=V W=E
$$

The following figure shows how the stored energy can vary as a function of the compression ratio (equal to the storage pressure) and the properties of the different materials. The ratio $\left(\mathrm{K}=\frac{\sigma}{\rho}\right)$ is the ratio of the tensile strength to the density of the material.

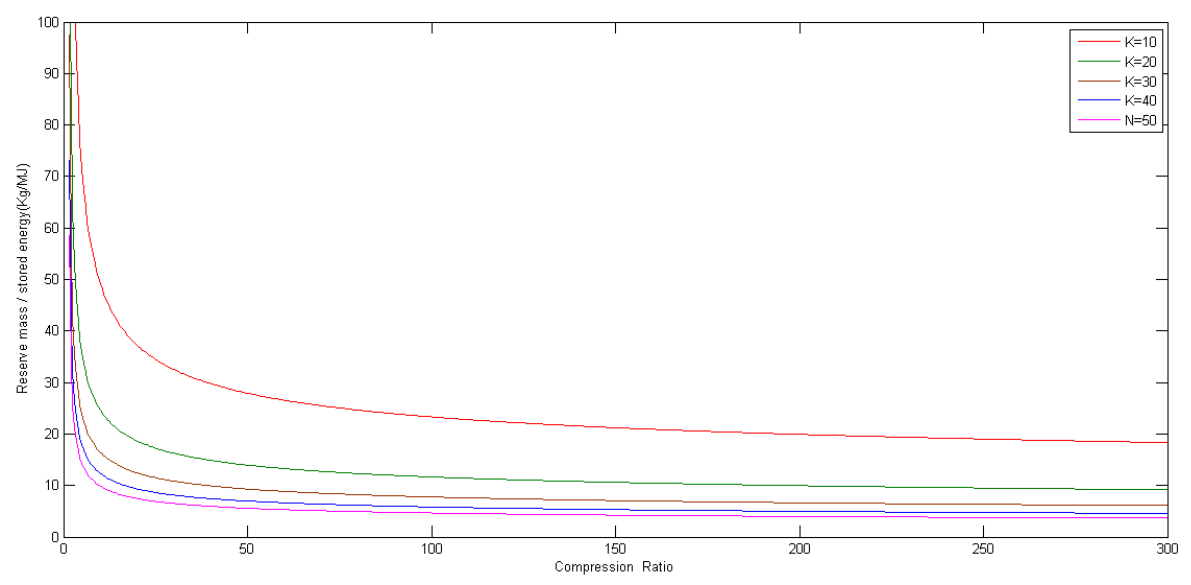

Figure 4. ratio (reservoir mass / stored energy) as a function of the compression ratio for different properties of the materials

It is easy to notice that the stored energy is higher the higher the compression ratio. The best performance (maximum stored energy and minimum reservoir mass) is obtained with the highest ratio $\left(\mathrm{K}=\frac{\sigma}{\rho}\right)$, for high tensile strength but relatively low density. 


\section{DIMENSIONING OF THE TANKS}

The dimensioning of reservoirs is a very important point in this study. They should not be too small or too large to ensure that excess energy can be stored and to limit congestion and engender a disproportionate investment. The sizing of the reservoirs is conditioned by the double study of the flow (variable) of the compressor (and therefore of the volume that can be stored in a given time) and the compressed air flow required by the CAM to drive the associated alternator and supply the isolated site with electricity [2][10]. Then to calculate the volume of the tanks two methods will be presented

\subsection{First method}

The first, a conventional method, is a function of: the maximum pressures, $P_{\max }$, and minimal, $P_{\min }$, allowable by the CAM, the desired autonomy a, maximum air flow required to power the compressed air motor, $\nu$. The volume will be calculated using the following formula:

$$
V=\frac{P_{a} a \nu}{P_{\max }-P_{\min }}
$$

\section{2. second method}

The second method for dimensioning the storage volume is to calculate the loading and discharge time of the tanks, given that the amount of air injected into the tank is variable and is a function of the power of the hybrid system absorbed by the compressor and of the air consumption of the CAM [11][15].

\subsubsection{Charging time}

To facilitate calculation, it is considered that the power absorbed to compress the air is constant. The instantaneous air flow rate can then be expressed as follows:

$$
\varepsilon=\frac{p_{c}}{E_{c}}
$$

With:

$P_{c}$ is the power consumed by the compressor .

$E_{c}$ the energy per unit mass necessary to compress the air at a given pressure.

On the other hand, by neglecting the losses by leakage of compressed air, the equation of conservation of the mass and the law of perfect gases make it possible to express the flow of air entering the volume $V_{r}$ of the storage tank as follows:

$$
\varepsilon=\frac{d m}{d t}=\frac{V_{r}}{T r} \frac{d p}{d t}
$$

By integrating the equation obtained from the preceding equations after having replaced each term $\left(P_{c}\right.$ and $\left.E_{c}\right)$ by its value, the charge time of a compressed air reservoir can be calculated from the following equation

$$
t_{c h}=\left(\frac{\left.\pi^{(} \lambda_{c h}+1\right)}{1+\lambda_{c h}}-\pi\right) N \tau_{c h}
$$

With :

$\lambda_{c h}=\frac{n-1}{N n}, \pi=\frac{P}{P_{a}}$ and $\tau$ is the time constant during the charging phase, defined by:

$$
\tau=P_{a} \frac{V}{P_{c}} \frac{C_{p}}{r}
$$

$\mathrm{V}$ is the volume of compressed air produced, $C_{p}$ is the mass heat of the compressed air. From the equation (17), The equation of the time constant $\tau$ Becomes:

$$
\tau=\frac{t_{c h}}{N\left(\frac{\pi\left(\lambda_{c h}+1\right)}{1+\lambda_{c h}}-\pi\right)}
$$

By replacing the value of $\tau$ in the equation (16), the expression of the product volume of compressed air becomes

$$
V=\frac{P_{c} r t_{c h}}{P_{a} C_{p} N\left(\frac{\pi\left(\lambda_{c h}+1\right)}{1+\lambda_{c h}}-\pi\right)}
$$




\subsubsection{Discharging time}

The discharge time of a compressed air reservoir may be calculated from the same the charging time, replacing $\varepsilon, \mathrm{P}$ and $\mathrm{E}$ respectively with the parameters of the compressed air motor [13].

$\varepsilon_{M}$, the mass flow of compressed air consumed by the MAC.

$P_{M}$, the power provided by the MAC.

$E_{M}$, the energy resulting from the expansion of the compressed air in the MAC.

The expression obtained from the discharge time is then written as follows [16][14].

$$
t_{d c h}=\left(\frac{\pi_{M}^{1+\lambda_{d c h}}}{1+\lambda_{d c h}}+\frac{\lambda_{d c h}}{1+\lambda_{d c h}}-\pi_{M}\right) N \tau_{d c h}
$$

With: $\lambda_{d c h}=\frac{n-1}{n N}, \pi_{M}=\frac{P_{M-i n}}{P_{M-o u}} ; \mathrm{N}$ is the number of expansion stages in the CAM and $\tau_{d c h}$ is the time constant during the discharge phase, defined by the following expression

$$
\tau_{d c h}=P_{a} \frac{V_{r}}{P_{M}} \frac{C_{p}}{r}
$$

$V_{r}$ is the volume of compressed air tank, $P_{M}$ is the power produced by the compressed air motor. The discharge time between 2 pressure levels can be calculated, as follows :

$$
t_{d c h-P_{1} P_{2}}=t_{d c h-P_{1}}-t_{d c h-P_{2}}=\left[\frac{\left(\pi_{P_{1}}^{1+\lambda_{d c h}}-\pi_{P_{2}}^{1+\lambda_{d c h}}\right)}{1+\lambda_{d c h}}+\left(\pi_{P_{2}}-\pi_{P_{1}}\right)\right] N \tau_{d c h}
$$

\section{RESULT AND DISCUSSION}

\subsection{The first method}

Figure 8 gives an idea of the dimensioning of the tank calculated from the equation 13 It shows that over the desired range is greater the greater the volume of air stored in the reservoir must be large. Thus, for an autonomy of 2 days, the volume necessary to store compressed air at 300 bar, will be of the order of $34 \mathrm{~m} 3$. On the other hand, this volume is enormous and oversized and it will be difficult to transport, to install a tank having this volume in an isolated site. In addition, the MAC will rarely operate at maximum flow when tank pressure is too low. This results from the fact that the tank will be recharged, once the pressure drops, using the excess energy that is available in this site in a fairly regular manner. Therefore, this method of sizing the reservoir will not be adopted for the rest of the calculation.

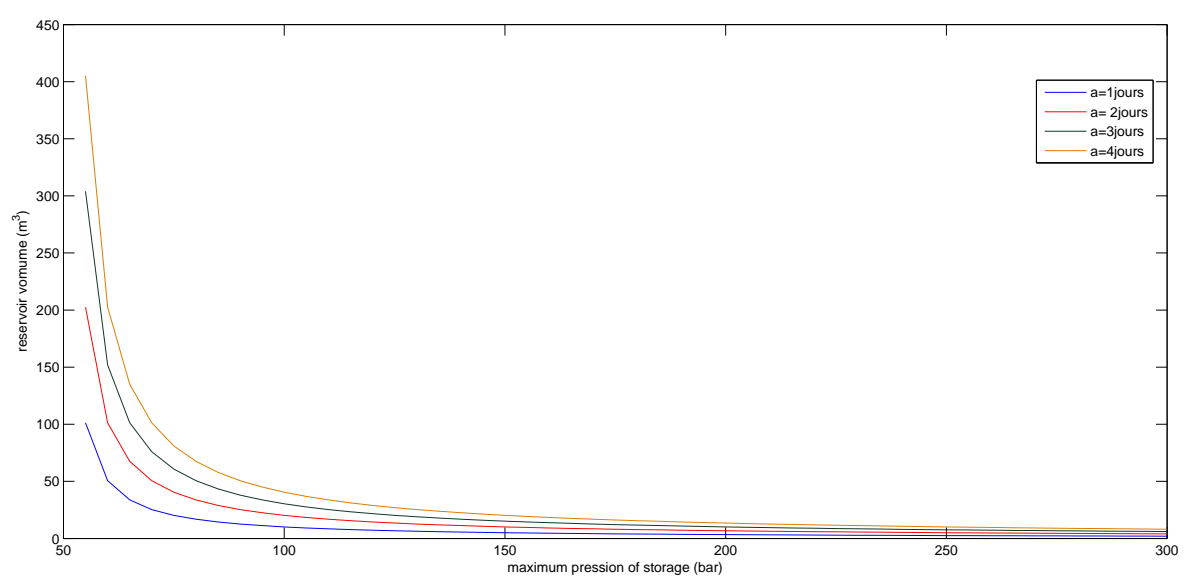

Figure 5. ratio (variation of the tank volume as a function of the maximum storage pressure and the autonomy 


\subsection{The second method}

\subsubsection{Charging time}

Figure 6 and Figure 7 show the charging time of a tank of 300 L volume, respectively, as a function of the number of stages of a compressor with $5 \mathrm{~kW}$ of power and the power absorbed by one compressor having 5 compression stages.

These figures show that the more the number of compressor stages increases or the more the electric power consumed to compress the air increases, the faster the charging time decreases.

A single-stage compressor can fill the $300 \mathrm{~L}$ volume in 3.5 hours, while approximately 2 hours will be sufficient to fill the same volume if the compression of air is done bay 5 stages. A time saving of about 43pc.

Thus, with a power of $20 \mathrm{~kW}$, it will take half an hour to fill a tank of $300 \mathrm{~L}$ whereas approximately 2 hours are required to fill the same volume when the excess power is $5 \mathrm{~kW}$. Precious time was saved, about $75 \mathrm{pc}$.

This results from the fact that the flow of compressed air injected into the reservoir increases proportionally with the increase in power.

However, these results still justify the choice of 5 stages of compression which has the advantages of increasing the reserve of compressed air and also prolonging the autonomy of the overall system.

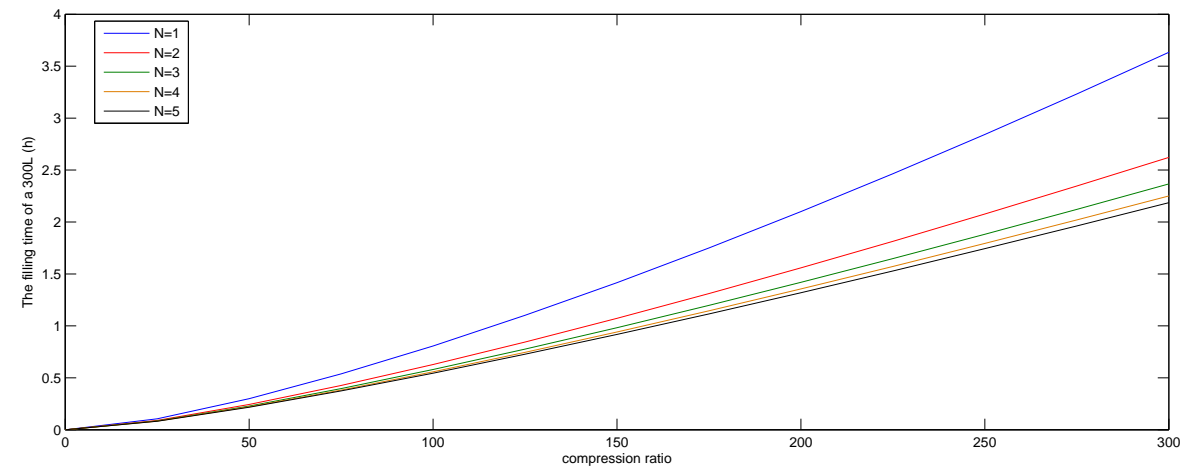

Figure 6. variation of charging time as a function of compression ratio and number of stages for a compressor of $5 \mathrm{KW}$ of power

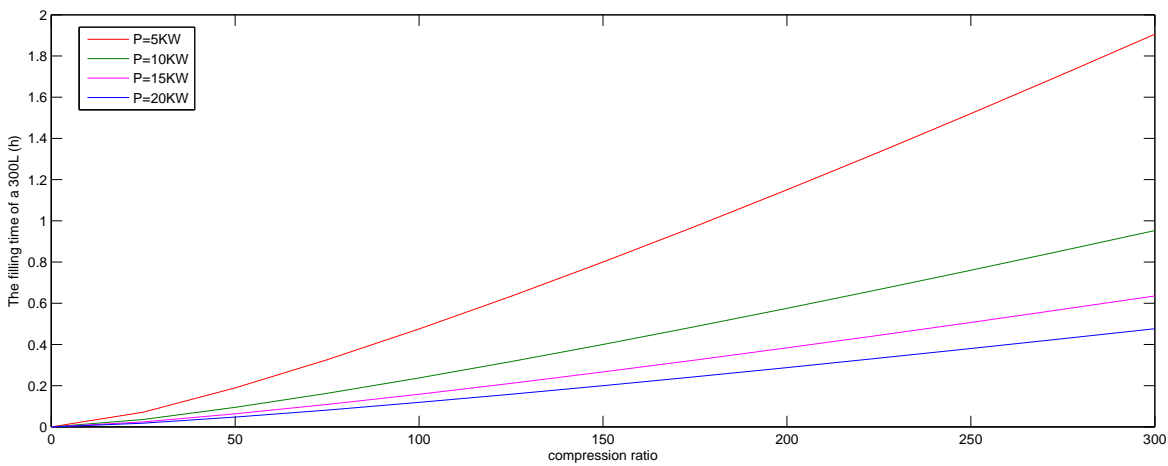

Figure 7. variation of the charging time as function of compression ratio and power consumed by the compressor 5 floor

It is easy to see from this figure that the amount of compressed air produced increases with the increase in the number of compression stages.A remarkable volume gain can be achieved if the compressor has 5 floor of compression is used instead of a single stage compressor. 


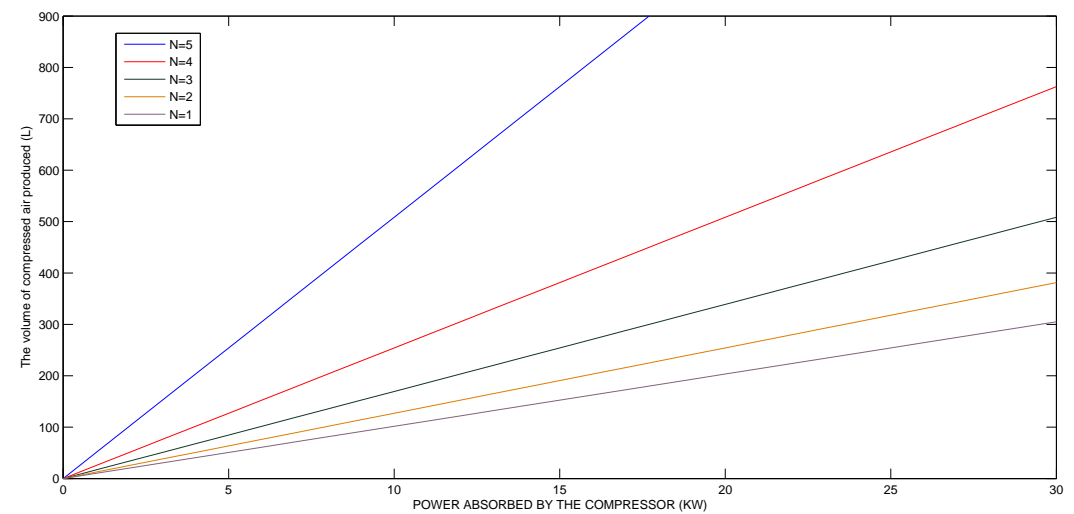

Figure 8. variation of volume of air produced as a function of the number of floors and of the power consumed by the compressor

\subsubsection{Discharging time}

The figures 9 and 10 show the variations of the discharge time, respectively, as a function of the maximum storage pressure and the number of expansion stages in the compressed air motor. The analysis of these figures shows that increasing the number of stages of a CAM serves to reduce the discharge time of the reservoir and consequently to accelerate the restoration of the stored energy in the form of compressed air, Thus, the higher the storage pressure, the longer the discharge time.

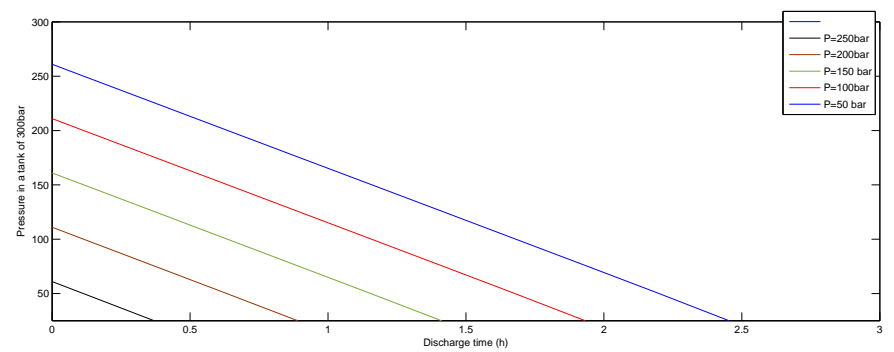

Figure 9. variation of pressure of the tank as a function of maximum storage pressure and discharge time

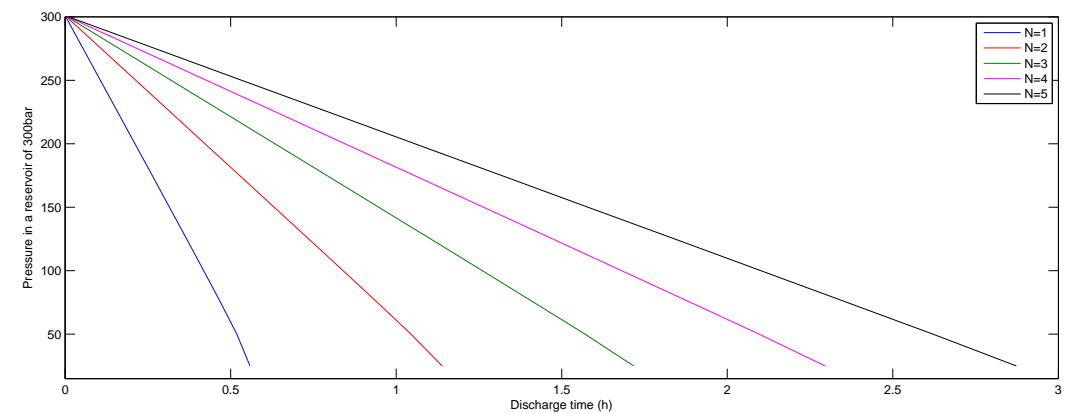

Figure 10. variation of pressure of the tank as a function of the discharge time and the number of stages

\section{CONCLUSION}

The fluctuating and intermittent nature of renewable energies requires the strengthening of the control of energy flows between supply and demand for electricity. energy storage then constitute a relevant response to 
this problematic,currently various solutions for storing green electricity exist (batteries, storage by compressed air or STEP - Stations of Transfer of Energy by Pumping). However, they do not permit massive storage of the intermittent energy produced over a long period of time. this study presented one of the main existing means of storing, the CAES (Compressed Air Energy Storage) or energy storage by compressing air which consists of storing energy in the form of compressed air, in an underground cavity (for a power of more than $100 \mathrm{MW}$ ), or in trivial tanks for small-scale storage, this is the case presented in this paper and then restore via a turbine producing electricity again.

\section{REFERENCES}

[1] Ilham rais and Hassan Mahmoudi, The control strategy for a hybrid windphotovoltaicsystem with compressed air storage element,"2nd International Conference on Electrical and Information Technologies ICEIT2016,(ICEIT), Tangiers, 2016, pp. 89-92.

[2] Hussein ibrahim, etude et conception dun generateur hybride delectricite de type olien-diesel avec lment de stockage dair comprim , universit du quebec chicoutimi, 2010.

[3] Minh Huynh Quang, Optimisation de la production de llectricit renouvelable pour site isol,University of Reims Champagne-Ardenne, 2013

[4] S. Rotthuser, Verfahren zur Berechnung und Untersuchung hydropneumatischer Speicher. PhD thesis, Rheinisch-Westflischen Technischen Hochshule, Aachen, 1993.

[5] K. W. Li, Applied Thermodynamics: Availability Method and Energy Conversion. Taylor and Francis, 1996.

[6] J. Lefvre, Air Comprim; Tome 1: Production. Paris - France: Encyclopdie industrielle, 1978.

[7] J. Faisandier and Coll., Mcanismes Hydrauliques et Pneumatiques. Paris France: Technique et Ingnierie, 8 ed., 1999.

[8] Sylvain LEMOFOUET - GATSI,investigation and optimisation of hybrid electricity storage systems based on compressed air and supercapacitors, COLE POLYTECHNIQUE FDRALE DE LAUSANNE,2006

[9] Ben Slama Sami;An Intelligent Power Management Investigation for StandAlone Hybrid System Using Short-Time Energy Storage;International Journal of Power Electronics and Drive System (IJPEDS);Vol. 8, No. 1, March 2017, pp. 367375.

[10] K.L. Sireesha, G. Kesava Rao ;Droop Characteristics of Doubly Fed Induction Generator Energy Storage Systems within Micro Grids,International Journal of Power Electronics and Drive System (IJPEDS), Vol. 6, No. 3, September 2015, pp. 429432

[11] D. Ganesh*, S. Moorthi**, H. Sudheer* ,D. Ganesh*, S. Moorthi**, H. Sudheer*;A Voltage Controller in Photo-Voltaic System with Battery Storage for Stand-Alone Applications ;International Journal of Power Electronics and Drive System (IJPEDS),Vol.2, No.1, March 2012, pp. 918

[12] U. MONASH, The pioneers: An anthology: Victor tatin (1843 - 1913), http://www.ctie.monash.edu.au/hargrave/tatin.html, vol. Access: january 2006.

[13] C. Sutton, Ucla study suggests air hybrid car could improve fuel efficiency, UCLA Engineer, vol. 10, pp. 4 $5,2003$.

[14] Hussein Ibrahim, Mariya Dimitrova, Adrian Ilinca, Jean Perron, Systme hybride oliendiesel avec stockage d'air comprim pour l'lectrification d'une station de tlcommunications isole. European Journal of Electrical Engineering, Volume 12/5-6 - 2009 -pp.701-731

[15] S. Lemofouet, Investigation and optimisation of hybrid electricity storage systems based on compressed air and supercapacitors, Thse de doctorat, cole Polytechnique Fdrale de Lausanne, Suisse, 2006.

[16] Adas Copco, LBZ Air Motors Manual, Tools Nr. 98338998 03, 2002, www.adascopcoairmotors. com 